\title{
Paradoxical effects of temperature in multiple sclerosis
}

\author{
W P HONAN, ${ }^{*} \dagger$ J R HERON, ${ }^{*} \dagger$ D H FOSTER, $\ddagger$ R S SNELGAR $\ddagger$ \\ From the Department of Neurology, ${ }^{*}$ North Staffordshire Royal Infirmary, Stoke-on-Trent, and the \\ Departments of Postgraduate Medicine $\dagger$ and of Communication and Neuroscience $\ddagger$, University of Keele, Keele, \\ Staffordshire, UK
}

SUMMARY Six cases of multiple sclerosis are reported in which cold produced a temporary exacerbation of symptoms and signs of the disease. Also, in one case investigated in detail by psychophysical methods, heating produced a paradoxical deterioration in vision and simultaneous improvement in sensory and motor function. The effect of temperature in multiple sclerosis is discussed and a physiological explanation for the paradoxical response to heating is suggested.

Environmental factors produce temporary changes in neurological function in multiple sclerosis. Uthoff ${ }^{1}$ described transient impairment of vision after exercise. Simons ${ }^{2}$ noted the adverse effect of heat, most commonly on muscle strength but also on spasticity, numbness and bladder symptoms. These initial observations have been confirmed by studies in which patients have been heated either by radiant heat or a hot bath. ${ }^{34}$ Heating can either cause exacerbation of existing signs or produce new signs; the most commonly affected are visual acuity, weakness and nystagmus. The clinical effects of heating usually happen immediately and resolve with cooling. ${ }^{45}$ In isolated cases a circadian variation with temperature has been recorded in visual acuity, ${ }^{6}$ visual acuity and visual fields ${ }^{7}$ and motor function. ${ }^{8}$ Although the effect of temperature in multiple sclerosis has been studied extensively, there have been few reports of worsening of symptoms in response to cold. ${ }^{29}$

We describe six patients with multiple sclerosis who reported deterioration of symptoms and signs in response to cold. Detailed clinical observations and psychophysical measurements are described in one patient, whose visual function worsened in the cold and improved with warmth. In addition, a paradoxical response to heating occurred, in which vision deteriorated and at the same time, sensory and motor function improved in the lower limbs. The effect of temperature in multiple sclerosis is discussed and an explanation for the paradoxical response is suggested.

Address for reprint requests: Dr J R Heron, The North Staffordshire Royal Infirmary, Princes Road, Hartshill, Stoke-on-Trent ST4 7LN, UK.

Received 21 November 1986. Accepted 5 January 1987

\section{Patients}

A summary of the clinical details of patients is given in the table. The patients were classified using McDonald and Halliday's criteria; ${ }^{11}$ appropriate investigations, including myelography and computed tomography, were used as necessary to exclude alternative diagnoses. Pattern-reversal visual evoked potentials (VEPs) and cerebrospinal fluid (CSF) immunoglobulin estimation were performed on all cases. The occurrence of abnormalities in these tests is recorded in the table.

The following characteristics were common to all cases presented: a relapsing and remitting form of the disease, mild disability, and an attack occurring within the previous 12 months which included spinal sensory symptoms. In all patients cold weather or exposure to cold was associated with the development or aggravation of paraesthesia. Other features included deterioration of motor function in cases 1 and 6; loss of sphincter control in cases 3 and 6 and impairment of vision in case 1 . Cold caused deterioration in all symptoms present at the time, except in case 5 in which the paroxysmal dysarthria was associated with fatigue but not with changes in temperature. Deterioration of symptoms usually occurred during the period of exposure to cold and in all cases relief occurred with warmth. The other clinical features in the table, including ataxia, vertigo, vomiting, and internuclear ophthalmoplegia in cases 2 and 4, were present in previous attacks but not at this examination. Cases 2-5 had no corticospinal tract dysfunction at the time of the present study. A hot bath, taken at home, did not produce a noticeable difference in cases 2-6. No patient reported adverse effects from alcohol or smoking tobacco.

Detailed observations Case 1 A 33 year old female patient delivered a healthy baby 6 years previously in the summer of 1979. Two months later she developed numbness and weakness of both legs. The numbness improved in 6 weeks, but mild weakness persisted. Six months later she had an episode of weakness of the right arm which recovered without treatment in 3 weeks. She was free of further attacks for 4 years until the birth of her second child. She suddenly developed 
Table Summary of patient details

\begin{tabular}{|c|c|c|c|c|c|c|c|c|c|c|}
\hline $\begin{array}{l}\text { Case } \\
\text { No }\end{array}$ & $\begin{array}{l}\text { Age } \\
(y r)\end{array}$ & Sex & $\begin{array}{l}\text { Duration } \\
(y r)\end{array}$ & $\begin{array}{l}\text { Number } \\
\text { attacks }\end{array}$ & Classification & EDSS & $C S F$ & $V E P$ & Clinical features & $\begin{array}{l}\text { Feature worse } \\
\text { with cold }\end{array}$ \\
\hline 1 & 33 & $\mathbf{F}$ & 6 & 4 & $\begin{array}{r}\text { Clinically } \\
\text { definite }\end{array}$ & $3 \cdot 5$ & + & + & $\begin{array}{l}\text { Paraesthesia } \\
\text { paraparesis } \\
\text { optic neuritis }\end{array}$ & $\begin{array}{l}\text { Paraesthesia } \\
\text { motor function } \\
\text { visual function }\end{array}$ \\
\hline 2 & 33 & $\mathbf{F}$ & 8 & 4 & $\begin{array}{l}\text { Early } \\
\text { probable }\end{array}$ & $2 \cdot 0$ & - & - & $\begin{array}{l}\text { Paraesthesia } \\
\text { vertigo, ataxia } \\
\text { internuclear } \\
\text { ophthalmoplegia } \\
\text { sphincter } \\
\text { disturbance }\end{array}$ & Paraesthesia \\
\hline 3 & 46 & $\mathbf{M}$ & 4 & 3 & $\begin{array}{l}\text { Early } \\
\text { probable }\end{array}$ & $3 \cdot 0$ & + & + & $\begin{array}{l}\text { Paraesthesia } \\
\text { paraparesis } \\
\text { sphincter } \\
\text { disturbance }\end{array}$ & $\begin{array}{l}\text { Paraesthesia } \\
\text { sphincter } \\
\text { disturbance }\end{array}$ \\
\hline 4 & 36 & $\mathrm{~F}$ & 13 & 5 & $\begin{array}{r}\text { Clinically } \\
\text { definite }\end{array}$ & $2 \cdot 0$ & + & - & $\begin{array}{l}\text { Paraesthesia } \\
\text { vomiting, ataxia } \\
\text { ataxic nystagmus }\end{array}$ & Paraesthesia \\
\hline 5 & 35 & $\mathbf{F}$ & 14 & 3 & $\begin{array}{r}\text { Clinically } \\
\text { definite }\end{array}$ & $1 \cdot 0$ & + & + & $\begin{array}{l}\text { Paraesthesia } \\
\text { optic neuritis } \\
\text { paroxysmal } \\
\text { dysarthria }\end{array}$ & Paraesthesia \\
\hline 6 & 26 & $\mathrm{~F}$ & 3 months & 1 & Suspected & $2 \cdot 0$ & + & - & $\begin{array}{c}\text { Paraesthesia } \\
\text { paraparesis } \\
\text { sphincter } \\
\text { disturbance }\end{array}$ & $\begin{array}{l}\text { Paraesthesia } \\
\text { motor function } \\
\text { sphincter } \\
\text { disturbance }\end{array}$ \\
\hline
\end{tabular}

EDSS, extended disability status scale (Kurtzke) ${ }^{10}$; CSF, cerebrospinal fluid; VEP, visual evoked potential; +, abnormal; -, normal.

symptoms in the left eye, consisting of a perception of a white, flickering light; it was usually located immediately lateral to the point of fixation, but at other times it migrated to other sectors in the left visual field. This abnormality was constant for several weeks, then became paroxysmal over a period of 6 months. Paroxysms were invariably produced by exposure to cold or cold weather; they also occurred occasionally in response to fatigue, bright lights or stress. The paroxysms lasted from a few minutes to a few hours. The only consistent preventative or alleviating factor was warmth. Three months after the onset of visual symptoms her walking deteriorated. The walking improved following a course of treatment with ACTH, although vision was unaltered.

She was investigated in the neurology unit in May 1985 , when visual acuity was $6 / 4$ in the right eye and $6 / 12$ in the left. Bjerrum screen visual fields showed a left paracentral scotoma. Pupillary reactions were normal. There was left optic atrophy. The other cranial nerves and nervous system examination was normal apart from absent abdominal reflexes. The CSF contained 8 lymphocytes per $\mathrm{mm}^{3}$, total protein $0.3 \mathrm{~g} / \mathrm{l}, \mathrm{IgG} 0.13 \mathrm{~g} / \mathrm{l}$ (normal: less than $0.05 \mathrm{~g} / \mathrm{l}$ ), IgG: Albumin ratio 1:2 (normal: greater than 1:3). The VEPs were abnormal in the left eye, consistent with demyelination. Colour vision tests showed three errors on the right and one in the left eye with Ishihara plates. The City University colour vision test was normal in both eyes. The FarnsworthMunsell 100 -Hue test ${ }^{12}$ was abnormal with 159 errors in the left eye and 115 errors in the right eye. Psychophysical tests were performed (see below).

She was discharged from hospital after investigations were completed and a diagnosis of clinically definite multiple sclerosis was made. Four days later her visual symptoms resolved and she reported her vision "had returned to normal". She attributed the improvement to the warm weather and daily sunbathing. She was investigated again one week after the initial psychophysical tests; acuity was then $6 / 6$ in the right eye and 6/9 in the left eye. The visual fields were normal and psychophysical tests were repeated.

The most recent relapse of multiple sclerosis occurred in November 1985, during icy wintry weather. Her feet were numb, "like blocks of ice", and the distance she was able to walk was restricted by increased stiffness and heaviness of the legs. Vision was unaffected. Her symptoms were aggravated by cold and relieved by warmth. On examination she had mild spastic paraparesis with impairment of all modalities of sensation in the lower limbs to the level of the midcalf. A paradoxical response to temperature was noted when she insisted that a hot bath resulted in improvement in both numbness and in walking, but caused a transient blurring of vision in the left eye. For this reason detailed psychophysical tests were carried out to investigate the effect of temperature change.

\section{Psychophysical tests}

Luminance critical flicker frequency (CFF) and luminance threshold were measured using a modified visual perimeter. ${ }^{13}$ For luminance threshold a white-light test stimulus, 15 min arc in diameter and duration $200 \mathrm{~ms}$, was presented on an auxiliary conditioning field, also $15 \mathrm{~min}$ arc in diameter. The luminance of the auxiliary field was $2.15 \mathrm{log} \mathrm{cd} . \mathrm{m}^{-2}$. A larger background field was also present to preserve the state of retinal adaptation; it was $21^{\circ}$ in diameter and its luminance was $1.86 \mathrm{log} \mathrm{cd} . \mathrm{m}^{-2}$. Luminance CFF was measured using the white-light $15 \mathrm{~min}$ arc test stimulus; the intensity was fixed at $2.54 \mathrm{log} \mathrm{cd} . \mathrm{m}^{-2}$ and the temporal profile consisted of a $3 \mathrm{~s}$ train of dark and light square wave pulses. The same large background field was present, but no auxiliary field.

Before each session of psychophysical tests, the scotoma 
was plotted on the Bjerrum screen and the apparatus was adjusted so that the test stimuli were presented on the area of the retina corresponding to the field defect. In this way we were able to obtain results specifically related to the damaged optic nerve fibres. The corresponding retinal site in the subject's right eye was used as a control. The tests were first performed in May 1985 in two sessions, separated by one week.

In November 1985, when she had symptoms of numbness and weakness of her legs, psychophysical tests were repeated to establish the effect of variation in temperature. The aims, details and possible complications ${ }^{14}$ of the tests were fully explained. The patient was convinced that cold produced a definite deterioration of her symptoms. Therefore she refused tests which involved cooling, although readily agreed to undergo tests involving heating.

The following visual parameters were measured: visual acuity, visual fields, luminance threshold and CFF. The tests were undertaken in the order listed above in two sessions, each lasting approximately 2 hours. The first session took place in the morning. The subject then had a two-hour rest away from the department. The vision laboratory was heated during the interval and the second session was then conducted in the afternoon. The procedure for the psychophysical tests was identical to that used in May 1985. Special care was taken to allow frequent rest periods. Ambient room temperature and patient oral temperature were recorded before and after each section of the test.

\section{Results}

In May 1985, the CFF was $14.6 \mathrm{~Hz}$ in the left eye, markedly reduced relative to a value of $32.1 \mathrm{~Hz}$ in the right eye. Luminance threshold was $2.76 \log \mathrm{cd} . \mathrm{m}^{-2}$ in the left eye.

A week later, after her symptoms had improved and visual fields were normal, psychophysical tests were repeated at the same retinal sites. CFF was 21.8 $\mathrm{Hz}$ in the left eye and $29.6 \mathrm{~Hz}$ in the right eye. Luminance threshold was $2.65 \mathrm{log} \mathrm{cd} . \mathrm{m}^{-2}$ in the left eye and $2 \cdot 17 \log \mathrm{cd} . \mathrm{m}^{-2}$ in the right eye.

These results confirmed the patient's subjective improvement in visual function in the left eye from the previous week; however, it remained impaired in comparison to the right eye, indicating a persistent subclinical deficit.

\section{Effect of temperature}

Detailed results were recorded in November 1985. The average ambient laboratory temperatures for the first and second sessions (before and after heating) were $19.4^{\circ} \mathrm{C}$ and $25^{\circ} \mathrm{C}$. The corresponding average patient temperatures were $36.4^{\circ} \mathrm{C}$ and $36 \cdot 6^{\circ} \mathrm{C}$. Visual acuity was $6 / 9$ in the left eye and $6 / 5$ in the right eye initially. After heating acuity was $6 / 9$ and $6 / 6$ in left and right eyes respectively. The visual field before heating showed a relative paracentral scotoma in the left eye. After heating the scotoma extended to the periphery, becoming a sector defect, and encompass- ing the blind spot. Luminance threshold in the left eye increased from $1.94 \mathrm{log} \mathrm{cd} . \mathrm{m}^{-2}$ before heating to 2.15 $\log$ cd. $\mathrm{m}^{-2}$ after heating. CFF in the left eye decreased from $26.4 \mathrm{~Hz}$ before heating to $23.1 \mathrm{~Hz}$ after heating. In the right eye CFF also decreased from $32.5 \mathrm{~Hz}$ before heating to $27.9 \mathrm{~Hz}$ after heating.

The results showed a definite worsening in visual function after heating. This effect occurred with an average increase in subject temperature of only $0 \cdot 2^{\circ} \mathrm{C}$, which was within the physiological temperature range.

Immediately after the heating session her legs improved. The stiffness and heaviness of the legs had eased, enabling her to walk around the department more quickly and freely. The numbness and cold sensation in her legs had also improved. On examination she had a mild spastic paraparesis; the ambulation index was $2 .{ }^{15}$ All sensory modalities were impaired in the left foot, but normal in the right foot. She was reassessed the following morning when her symptoms had returned to their pre-heating level. On examination the spastic paraparesis was unchanged, however the ambulation index was 3 and sensory testing now showed impairment of all modalities had extended in both lower limbs back up to mid-calf level.

We were therefore able to confirm that heating produced a paradoxical improvement of sensory and motor function, with simultaneous deterioration of vision.

\section{Discussion}

In addition to causing deterioration in clinical signs, heating multiple sclerosis patients has produced abnormalities in psychophysical tests of visual function including CFF ${ }^{16}$ and two flash resolution. ${ }^{17}$ The production of new signs following the hot bath test has been utilised in some institutions as a diagnostic test for multiple sclerosis. ${ }^{18}$ Although the effects of heating are usually transient, cases of prolonged disability following the hot bath test have since been recorded. ${ }^{14}$ This finding has diminished the value and use of the hot bath test in most neurological units, including our own. Conversely, exposing patients to cold may improve symptoms. Watson ${ }^{19}$ lowered the body temperature in six cases of multiple sclerosis with improvement in symptoms and signs that were currently present. The improvement lasted only while the body temperature remained low.

Fever therapy for multiple sclerosis has been used, but was shown to be unhelpful. ${ }^{20}$ Lindemulder ${ }^{21}$ suggested a hot bath might improve symptoms in multiple sclerosis. Twelve patients were studied, of whom four appeared to improve, two deteriorated and the remainder were unchanged. The author was cautious 
in interpreting the results, in the light of the known variability of the disease.

An adverse response to cold in multiple sclerosis is unusual. Simons, ${ }^{2}$ in his study of 21 patients' subjective reactions to heat and cold, reported a minority of six cases in which cold aggravated numbness and bladder symptoms. Geller ${ }^{9}$ reported a single case in which cold produced a worsening of motor symptoms. Interestingly this case also developed internuclear ophthalmoplegia following the hot-bath test.

Some patients with multiple sclerosis are extremely sensitive to alteration in temperature within the normal physiological range. Namerow ${ }^{7}$ reported a single case in which visual acuity was dramatically reduced with a temperature increase of just $0 \cdot 25^{\circ} \mathrm{C}$. Other authors ${ }^{468}$ have reported increased clinical abnormalities in patients with temperature increases in the order of $0.5^{\circ} \mathrm{C}$.

All the patients we report are convinced of the adverse effect of cold on their symptoms and of the improvement by warmth. Although the majority of the evidence presented here is subjective, a rational physiological explanation is required. Previously suggested explanations for deterioration in cold have included overdressing, overheating indoors, or elevation of body temperature in response to cold. ${ }^{19}$ Shivering due to cold leading to a rise in body temperature has been reported in a case of multiple sclerosis with deterioration in visual acuity. ${ }^{7}$ Although these hypotheses may account for the effect of cold, they do not explain the paradoxical reaction to heating observed in case 1 .

We suggest that there is a reasonable physiological explanation for the paradoxical effect of heating. Conduction velocity in normal nerve fibres has been shown to increase linearly with temperature through a range of 28 to $40^{\circ} \mathrm{C}^{22} \mathrm{~A}$ further rise in temperature can cause conduction block. In experimentally demyelinated nerves, conduction block has been produced by an increase in temperature of only $0.5^{\circ} \mathrm{C}$, which occurred within the normal physiological range. ${ }^{22} 23$

The effect of temperature on nerve conduction velocity in multiple sclerosis has been studied using a theoretical model. ${ }^{24}$ The greater the degree of demyelination, the lower the temperature required to produce conduction block. Also, before block occurred, conduction velocity continued to increase with rising temperatures, similar to that which occurred in the normal nerve. However, the relationship between blocking temperature and the relative degree of demyelination was not linear; at a critical degree of demyelination, conduction block occurred with a very small rise in temperature. The obvious clinical parallel of this model is the well known sudden deterioration of function in multiple sclerosis with very small rises in temperature.
We suggest that the theoretical model could also explain the paradoxical observations in case 1 , if during the most recent attack in November 1985 there was a disproportionate degree of demyelination in the visual pathway compared with that in the spinal sensory pathway. Then the model predicts that at a critical temperature conduction block would occur in the visual pathway, but not in the spinal sensory pathway where conduction velocity would be increasing. The clinical effect of this discrepancy could be simultaneous deterioration of vision and improvement of spinal sensory symptoms in the same patient.

Caution is needed when extrapolating from a theoretical model to clinical function; conduction velocity and conduction block in the region of a demyelinated plaque may only represent a partial explanation. However, our suggestion that sensory perception thresholds vary with temperature change is supported by evidence that vibration thresholds increase in normal subjects exposed to cold. ${ }^{25}$ Heating has also produced improvement in visual perception in an isolated case of multiple sclerosis. ${ }^{26}$ Further circumstantial support comes from the theoretical model as improvement with heating might be expected to occur mainly in situations where the degree of demyelination was relatively mild. This conclusion is supported by our series of patients, none of whom were advanced cases of multiple sclerosis.

This research was supported by awards from the Multiple Sclerosis Society of Great Britain and Northern Ireland (WPH), and the Medical Research Council (RSS).

\section{References}

1 Uthoff $\mathrm{W}$. Untersuchungen uber die bei der multiplen herdsklerose vorkommenden augenstorungen. Arch Psychiat Nervrankh 1890;21:55-116, 303-410.

2 Simons DJ. A note on the effect of heat and of cold upon certain symptoms of multiple sclerosis. Bull Neurol Inst NY 1937;6:385-6.

3 Guthrie TC. Visual and motor changes in patients with multiple sclerosis. Arch Neurol 1951;65:437-51.

4 Nelson DA, McDowell F. The effects of induced hyperthermia on patients with multiple sclerosis. J Neurol Neurosurg Psychiatry 1959;22:113-6.

5 Michael JA, Davis FA. Effects of induced hyperthermia in multiple sclerosis: Differences in visual acuity during heating and recovery phases. Acta Neurol Scand 1973;49:141-51.

6 Hopper CL, Matthews CG, Cleeland CS. Symptom instability and thermoregulation in multiple sclerosis. Neurology 1972;22:142-8.

7 Namerow NS. Circadian temperature rhythm and vision in multiple sclerosis. Neurology 1968;18:417-22.

8 Davis FA, Michael JA, Tomaszewski JS. Fluctuation of motor function in multiple sclerosis related to circadian temperature variations. Dis Nerve System 1973;34:33-6.

9 Geller M. Appearance of signs and symptoms of multiple sclero- 
sis in response to cold. Mount Sinai J Med 1974;41:127-30.

10 Kurtzke JF. Rating neurologic impairment in multiple sclerosis: an expanded disability status scale (EDSS). Neurology 1983;33:1444-52.

11 McDonald WI, Halliday AM. Diagnosis and classification of multiple sclerosis. Br Med Bull 1977;33:4-9.

12 Farnsworth D. The Farnsworth-Munsell 100-Hue test. In: Pokorny J, Smith VC, Verriest G, Pinkers AJLG, eds. Congenital and Acquired Color Vision Defects. New York: Grune and Stratton, 1979:93-7.

13 Foster DH, Snelgar RS, Heron JR. Nonselective losses in foveal chromatic and luminance sensitivity in multiple sclerosis. Invest Ophthalmol Vis Sci 1985;26:1431-41.

14 Berger JR, Sheremata WA. Persistent neurological deficit precipitated by hot bath test in multiple sclerosis. JAMA 1983;249:1751-3.

15 Hauser SL, Dawson DM, Lehrich JR, et al. Intensive immunosuppression in progressive multiple sclerosis. A randomised three-arm study of high-dose intravenous cyclophosphamide, plasma exchange and ACTH. $N$ Engl J Med 1983;308:173-80.

16 Namerow NS. Temperature effect on critical flicker fusion in multiple sclerosis. Arch Neurol 1971;25:269-75.

17 Galvin RJ, Regan D, Heron JR. A possible means of monitoring the progress of demyelination in multiple sclerosis: Effect of body temperature on visual perception of double light flashes.
J Neurol Neurosurg Psychiatry 1976;39:861-5.

18 Davis FA. The hot bath test in the diagnosis of multiple sclerosis. J Mount Sinai Hosp 1966;33:280-2.

19 Watson CW. Effect of lowering of body temperature on the symptoms and signs of multiple sclerosis. New Engl J Med 1959;261:1253-9.

20 McAlpine D, Compston ND, Lumsden CE. Multiple Sclerosis. Edinburgh: Churchill Livingstone, 1955.

21 Lindemulder FG. The therapeutic value of high temperature baths in multiple sclerosis. J Nerv Ment Dis 1930;72:154-8.

22 Rasminsky M. The effects of temperature on conduction in demyelinated single nerve fibres. Arch Neurol 1973;28:287-92.

23 Davis FA. Axonal conduction studies based on some considerations of temperature effects in multiple sclerosis. Electrocencephalogr Clin Neurophysiol 1970;28:281-6.

24 Schauf CL, Davis FA. Impulse conduction in multiple sclerosis: A theoretical basis for modification by temperature and pharmacological agents. J Neurol Neurosurg Psychiatry 1974; 37:152-61.

25 Koradecka D. Changes in the threshold of vibration sensibility depending on skin temperature. Acta Physiol Pol 1974; 25:207-14.

26 Regan D, Murray TJ, Silver R. Effect of body temperature on visual evoked potential delay and visual perception in multiple sclerosis. J Neurol Neurosurg Psychiatry 1977;40:1083-91. 